\title{
Endovascular coil visible in a visible vessel
}

A 59-year-old woman collapsed while she was being admitted for chemotherapy for stage IV ovarian cancer. After large-volume resuscitation, upper gastrointestinal endoscopy was performed because of hematemesis. A large ulcer $(2 \times 2 \mathrm{~cm})$ in the posterior wall of the duodenal bulb with a large, actively bleeding visible vessel (estimated diameter 5-6 mm) was seen. Despite repeated local epinephrine injections, heater probe coagulation and endoscopic clipping, arterial bleeding persisted. These endoscopic hemostatic techniques probably failed because the diameter of the bleeding vessel was too large; endoscopic visibility was bad due to persistent fulminant bleeding and the location of the ulcer [1,2]. Emergency surgery was considered too invasive because of the patient's medical history. Angiography showed massive duodenal bleeding after contrast injection in the gastroduodenal artery. Multiple endovascular coils were successfully placed both distal and proximal to the bleeding focus. - Figure 1 shows selective angiography of the common hepatic artery. Multiple coils are present in the gastroduodenal artery, obstructing the passage of contrast fluid. The patient recovered soon after this intervention. After 4 days, upper gastrointestinal endoscopy was performed because of a slight decrease in the hemoglobin level. A coil was clearly seen in the center of the visible vessel (॰ Figure 2).

Endoscopy_UCTN_Code_CCL_1AB_2AZ_3AD Endoscopy_UCTN_Code_CCL_1AB_2AF

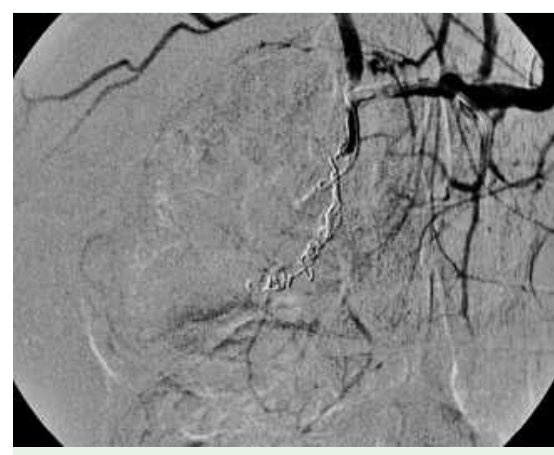

Figure 1 Selective angiography of the common hepatic artery showing multiple coils in the gastroduodenal artery resulting in hemostasis.

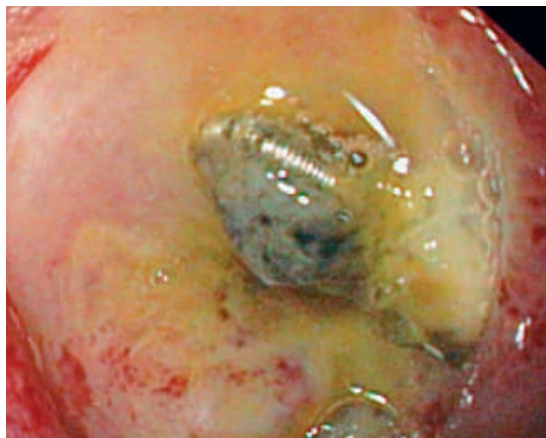

Figure 2 Endoscopic view of the base of the ulcer with a coil located in the center of the previously bleeding vessel.

\section{F. P. Vleggaar ${ }^{1}$, D. R. Rutgers ${ }^{2}$}

1 Department of Gastroenterology, University Medical Center Utrecht, The Netherlands

2 Department of Radiology, University Medical Center Utrecht, The Netherlands
References

1 Peng YC, Chen SY, Tung CF et al. Factors associated with failure of initial endoscopic hemoclip hemostasis for upper gastrointestinal bleeding. J Clin Gastroenterol 2006; 40: $25-28$

2 Arasaradman RP, Donelly MT. Acute endoscopic intervention in non-variceal upper gastrointestinal bleeding. Postgrad Med J 2005; 81: $92-98$

Bibliography

DOI 10.1055/s-2007-966414

Endoscopy 2007; 39: E203

(c) Georg Thieme Verlag KG Stuttgart · New York . ISSN 0013-726X

\section{Corresponding author}

F. P. Vleggaar

UMC Utrecht

Heidelberglaan 100

3584 CX Utrecht

The Netherlands

Fax: +31-30-2505533

f.vleggaar@umcutrecht.nl 